\title{
AGIR A FAVOR DA INCLUSÃO: IFMT EM AÇÃO
}

\author{
ACTUANDO EN FAVOR DE LA INCLUSIÓN: IFMT EN ACCIÓN
}

ACTING IN FAVOUR OF INCLUSION: IFMT IN ACTION

\author{
Suammy Priscila Rodrigues Leite CORDEIRO ${ }^{1}$
}

RESUMO: Esta pesquisa apresenta um estudo voltado para políticas e práticas de inclusão e valorização da igualdade no Instituto Federal de Educação, Ciência e Tecnologia de Mato Grosso - IFMT, que atende, em todas as modalidades de ensino, pesquisa e extensão, de forma verticalizada aproximadamente 25.400 alunos, à distância e presencialmente, através de 14 campi espalhados no Estado. Sua missão "Educar para a vida e para o trabalho", reflete o compromisso com a inclusão social, uma vez que explicita e acolhe as diferenças, sem, contudo, desvalorizar as especificidades de cada sujeito. A pesquisa de abordagem qualitativa comprova o interesse que o IFMT tem demonstrado em atender as legislações vigentes, se caracterizando, assim, como pesquisa documental. A análise dos dados considera três eixos temáticos: Legislação vigente no campo dos direitos humanos e inclusão, ações em realização no IFMT e por fim, avaliação conceitual do cumprimento dos parâmetros legais.

PALAVRAS-CHAVE: IFMT. Legislação. Inclusão. Ações.

RESUMEN: Esta investigación presenta un estudio relacionado con las políticas y prácticas de inclusión y promoción de la igualdad en el Instituto Federal de Educación, Ciencia y Tecnología de Mato Grosso - IFMT, que sirve en todos los tipos de enseñanza, investigación y extensión en forma vertical aproximadamente 25.400 estudiantes en la distancia y en persona, a través de 14 campus en todo el estado. Su misión "educar para la vida y el trabajo" refleja el compromiso con la inclusión social, de forma explícita y abierto a las especificidades, pero sin depreciar las características específicas de cada sujeto. La investigación cualitativa muestra el interés que se ha mostrado en IFMT cumple con la legislación vigente, la caracterización, así como la investigación documental. Análisis de los datos se analizan tres temas principales: la legislación actual en materia de derechos humanos y la inclusión, acciones realización en IFMT y evaluación por último, conceptual del cumplimiento de los parámetros legales.

PALABRAS CLAVE: IFMT. Legislación de inclusión. Acciones.

1 Prof. Ma. Suammy Priscila Rodrigues Leite Cordeiro, mestre em Estudos Linguísticos pela Universidade Federal do Mato Grosso - UFMT e doutoranda pela Universidade de Lisboa. Docente do Instituto Federal de Ensino, Ciências e Tecnologia do Mato Grosso - IFMT. Contato: suammypriscila@gmail.com 
ABSTRACT: This research presents a study focused on policies and inclusion practices and enhancement of equality at the Federal Institute of Education, Science and Mato Grosso Technology - IFMT, which serves in all types of education, research and extension, vertical form approximately 25,400 students, at a distance and in person, through 14 campuses throughout the state. It's mission "Educating for life and work" reflects the commitment to social inclusion, as explicitly and welcomes the differences without, depreciate the specifics of each subject. The qualitative research shows the interest that has been shown in IFMT meet the current legislation, characterizing, as well as documentary research. Data analysis considers three main themes: Current legislation in the field of human rights and inclusion, actions realization in IFMT and finally, conceptual evaluation of compliance with legal parameters.

KEYWORDS: IFMT. Legislation. Inclusion. Actions

\section{Introdução}

O Brasil é um país grande com realidades geográficas, sociais e econômicas díspares. Com o advento das transformações sociais, os conceitos que abarcam a "Inclusão" vêm sendo bastante utilizados e amplamente discutidos, efetivamente no meio escolar.

Decorrendo de mobilizações advindas dos movimentos sociais, na esperança de impulsionar ações mais efetivas (agendas, programas e projetos) e buscando a materialização da defesa e promoção dos direitos humanos, surgem novos documentos no panorama nacional e local: os Programas Nacionais, Estaduais e Municipais de Direitos Humanos, o Estatuto da Criança e do Adolescente - ECA, as legislações de combate à discriminação étnico-racial e à tortura etc.

Observa-se, contudo, que, mesmo diante dessa realidade de exigências pela igualdade, as movimentações sociais para alcançar esse fim continuam distantes da realidade e da concretização de um Estado Democrático de Direito. Persiste, assim, um distanciamento entre os marcos normativos e a realidade da maioria da população brasileira. Tal realidade reflete um contexto nacional de desigualdades e exclusão social, econômica, racial, étnica e cultural, em consequiência de um padrão de Estado fundamentado na concepção neoliberal, no qual as políticas públicas priorizaram os direitos civis e políticos, em detrimento dos direitos humanos, individuais e coletivos.

Assim, este trabalho apresenta um estudo sobre políticas e práticas de inclusão no Instituto Federal de Educação, Ciência e Tecnologia de Mato Grosso - IFMT. Carateriza-se a realidade local, em confronto com os normativos nacionais e 
apresentam-se as linhas de atuação da instituição com vista a dar respostas de qualidade aos utentes. Mostra-se de que modo a articulação de pessoas e instituições, e o desenvolvimento de ações de programas de inclusão e diversidade do Ministério da Educação - MEC constroem melhorias a níveis diferenciados no atendimento de uma população diversa.

Reflete-se sobre programas no âmbito interno, envolvendo gestores, sociólogos, psicólogos, pedagogos, assistentes sociais, orientadores educacionais, técnicos administrativos, técnicos em assuntos educacionais, docentes, discentes e pais: Estes programas têm como objetivo criar na instituição a cultura da "educação para a convivência", a aceitação da diversidade e, principalmente, intentar a quebra das barreiras arquitetônicas, educacionais e atitudinais.

Desta forma, as questões referentes à acessibilidade, inclusão e diversidade, insistentemente, são tratadas, mesmo no cenário atual, ainda e somente por meio do viés legal, o que nos leva a buscar cada vez mais a mudança da realidade, através da defesa da educação para a aceitação das diferenças, no intuito de educarmos sujeitos conscientes de que todas as pessoas, independentemente de sua condição social, raça, cor, orientação sexual, limitação e outros, precisam ser percebidas como seres humanos com direitos básicos garantidos pela legislação.

\section{A Instituição}

O Instituto Federal de Educação, Ciência e Tecnologia do Mato Grosso - IFMT constitui-se, através da Lei ${ }^{\circ} 11.892 / 2008$, em uma autarquia instituída pelo Governo Federal Brasileiro e, segundo o seu Plano de Desenvolvimento Instituicional - $\mathrm{PDI}^{2}$, possui atualmente 14 campi em funcionamento, nas seguintes localizações: Alta Floresta, Barra do Garças, Cáceres, Campo Novo do Parecis, Confresa, Cuiabá Octayde Jorge da Silva, Cuiabá - Bela Vista, Juína, Pontes e Lacerda, Primavera do Leste, São Vicente, Sorriso, Rondonópolis e Várzea Grande. Contando ainda com quatro núcleos avançados, localizados nos municípios de Jaciara, Campo Verde,

2 O PDI é um grande planejamento da Instituição que dever ser reelaborado a cada cinco anos. Como Instituição de ensino que possui, entre outras modalidades, a educação superior, os Institutos Federais devem ter um Plano de Desenvolvimento Institucional, requisito imprescindível para o reconhecimento de avaliação de cursos superiores, de acordo com o Decreto $n^{\circ}$ 5.773/2006. (http://pdi.ifmt.edu.br/?page_id=2) 
Sapezal, Jauru, e os campi avançados em processo de implantação, sendo eles: Tangará da Serra, Diamantino, Lucas do Rio Verde e Sinop (IFMT, 2014).

Na capital, além dos três campi em funcionamento, está localizada também a reitoria, que é o centro administrativo do IFMT, que se divide em seis setores: O Gabinete do reitor e as Pró-reitorias de Ensino - PROEN, de Extensão - PROEX, de Pesquisa - PROPES, Administrativa - PROAD e Institucional - PRODIN.

Esta instituição de ensino tem como meta principal, promover desenvolvimento local em seu contexto macro (País), mediano (Estado/Região) e micro (Municípios) conforme as realidades que nos são apresentadas em cada localidade, atendendo à legislação e a uma demanda social e econômica, conforme estabelecido no artigo $6^{\circ}$ da Lei de criação dos IFs:

ofertar educação profissional e tecnológica, em todos os seus níveis e modalidades, formando e qualificando cidadãos com vistas na atuação profissional nos diversos setores da economia, com ênfase no desenvolvimento socioeconômico local, regional e nacional (BRASIL, 2008).

Além do ensino, o IFMT oferta desenvolvimento de trabalhos voltados para a pesquisa e extensão de forma verticalizada (do Ensino Médio à pós-graduação), a aproximadamente 17.800 alunos regulares presenciais em todas as regiões do Estado de Mato Grosso, com previsão a 22 mil alunos até o ano de 2018, meta proposta pela instutição através do PDI 2014-2018, aprovado em 2014. Estamos presentes ainda, através da UAB (Universidade Aberta do Brasil), em 15 outros municípios do Estado, ofertando ensino a distância para cerca de 900 graduandos em cursos superiores e cerca de 6.700 alunos de programas de EAD - Educação à distância. Ofertamos também cursos de pós-graduação Lato Sensu e Stricto Sensu, além de apoiar e realizar programas socais do Governo Federal voltados para a formação profissional e elevação da escolaridade de pessoas, inclusive em situação de vulnerabilidade social (IFMT, 2014).

É nesse contexto que o IFMT tem definidas como metas fundamentais, inclusive em seu Estatuto, publicado no Diário Oficial da União de 04.09.2009:

Art. $4^{\circ}$ - O IFMT, em sua atuação, observa os seguintes princípios norteadores: I - compromisso com a justiça social, equidade, cidadania, ética, preservação do meio ambiente, transparência, publicidade e gestão democrática; II - verticalização do ensino e sua integração com a pesquisa e a extensão; III - eficácia nas respostas de 
formação profissional, difusão do conhecimento científico e tecnológico e suporte aos arranjos produtivos educacionais, locais, sociais e culturais; IV - inclusão de pessoas com deficiências e com necessidades educacionais especiais; e V - natureza pública e gratuita do ensino regular, sob a responsabilidade da União.

A missão da Instituição "Educar para a vida e para o trabalho" afirma o compromisso com a inclusão social, uma vez que explicita e acolhe as diferenças, sem, contudo desvalorizar as especificidades de cada sujeito, como único. Nesta perspectiva, o IFMT prima pela concretização de relações que prezam pelo respeito à pessoa humana e pela inclusão de todos.

\section{A Inclusão no IFMT}

No propósito de melhor atender as especificidades nos campi, há dois anos foi criada, como iniciativa da Reitoria, a Coordenação de Políticas de Diversidade e Inclusão - CPDI, que funciona na própria Reitoria, especificamente na Pró-Reitoria de Ensino - PROEN, e é responsável por realizar o acompanhamento, monitoramento e orientação na execução das políticas de educação e direitos humanos no IFMT, através das ações dos Núcleos de Atendimento às Pessoas com Necessidades Específicas NAPNE, em funcionamento em cada um dos campi, visando à articulação de pessoas, instituições, e ao desenvolvimento de ações de programas de inclusão e diversidade do Ministério da Educação - MEC.

Essas ações são realizadas no âmbito interno e envolvem gestores, sociólogos, psicólogos, pedagogos, assistentes sociais, orientadores educacionais, técnicos administrativos, técnicos em assuntos educacionais, docentes, discentes e pais, com o objetivo de criar na instituição a cultura da "educação para a convivência", aceitação da diversidade e, principalmente, buscar a quebra das barreiras arquitetônicas, educacionais e atitudinais.

Com a inauguração desta nova instância do IFMT, que, aliás, não é comum em outros Institutos Federais no Brasil, começamos a perceber as necessidades em observar as diversas legislações existentes no Brasil e da falta de cumprimento dela nesta instituição de educação, e buscamos então atentar para estes fatos. E como coordenador 
deste núcleo de inclusão, delineamos várias linhas de intervenção, traçadas no PDI, a saber:

- Instituir ações de defesa da diversidade e da inclusão social no IFMT;

- Instituir a política de acessibilidade e apoio às pessoas com deficiência (PcDs) no IFMT;

- Implantação de NAPNES com estrutura e equipe multiprofissional em todos os campi do IFMT;

- Adequação de todos os prédios já existentes do IFMT, promovendo a acessibilidade física por meio da remoção de barreiras arquitetônicas;

- Articular o processo de capacitação em LIBRAS para os servidores do IFMT;

- Fomentar o desenvolvimento de políticas, projetos e ações afirmativas em respeito às diversidades (sexual, de gênero, étnico-racial, religiosa, socioeconômica, etc.) e na busca da inclusão social e da igualdade;

- Incentivar o desenvolvimento de tecnologias voltadas à inclusão e diversidade no âmbito do IFMT;

- Instituir o programa de prevenção e promoção à saúde no IFMT;

- Fomentar Políticas de Ação Afirmativa para garantir o acesso e a permanência dos alunos em vulnerabilidade;

- Incentivar o desenvolvimento de recursos didáticos e pedagógicos voltados à inclusão e diversidade no âmbito do IFMT.

Salienta-se que o âmbito da nossa atuação se respalda em documentos legais que enquadram as linhas de ação já delineadas. De entre esses documentos, destaca-se, pelo impacto que poderia ter na realidade das instituições de ensino, o Plano Nacional de Educação Especial de 1994, que consistia em ampliar as matrículas na educação especial:

\begin{abstract}
A Política Nacional de Educação Especial compreende, portanto, o enunciado de um conjunto de objetivos destinados a garantir o atendimento educacional do alunado portador de necessidades especiais, cujo direito à igualdade de oportunidades nem sempre é respeitado. A expectativa, a partir da concretização desse enunciado, é de que, até o final do século, o número de alunos atendidos cresça pelo menos 25 por cento, o que ainda pode ser considerado muito pouco, tendo em vista a atual demanda, estimada em torno de 10 por cento da população, dos quais apenas cerca de 1 por cento recebe, atualmente, atendimento educacional (PNE, 1994, p. 7-8).
\end{abstract}

Ainda a Lei $\mathrm{N}^{\circ}$ 9394/96, de 20 de dezembro de 1996, conhecida comumente no âmbito educacional pela sigla LDB - Lei de Diretrizes e Bases da Educação Nacional é o alicerce em que se sustenta a Educação do País. Contendo 298 metas para todos os níveis e modalidades de ensino, contempla também importantes questões sobre a formação de professores, financiamento e gestão da educação no Brasil, referindo igualmente à superação da desigualdade e da exclusão. 
A LDB dispõe sobre a regulamentação do sistema de educação do Brasil, baseada nos princípios presentes na Constituição Federal (1988). Seu Art. 58, parágrafo primeiro, refere aos serviços de apoio especializado na escola regular, para atender às peculiaridades das pessoas com necessidades educacionais específicas (PNEE), e seu Art. 59 assegura aos educandos com necessidades especiais:

I - currículos, métodos, técnicas, recursos educativos e organização, específicos para atender às suas necessidades;

II - terminalidade específica para aqueles que não atingiram o nível exigido para a conclusão do programa escolar em virtude de suas deficiências, e aceleração para concluir em menor tempo o programa escolar para os superdotados;

III - professores com especialização adequada em nível médio ou superior, para atendimento especializado, bem como professores de ensino regular capacitados para a integração desses estudantes nas classes comuns.

IV - educação especial para o trabalho, visando sua efetiva integração na vida em sociedade. (BRASIL, 1996)

Equaciona-se o trabalho realizado no IFMT com vista a explanar a trajetória do cumprimento legislacional das práticas inclusivas e direitos humanos, mostrando os avanços e atrasos deste cumprimento. Partindo de análise documental faremos confronto entre a legislação e a realidade vivenciada no IFMT.

\section{Resultados das Ações}

Quando avaliamos os planos de ação já concretizados e os que estão por se realizar, fica claro que, por um lado, há avanços no cumprimento da legislação por parte do IFMT, bem como interesse da instituição em realizar atendimento adequado às pessoas com deficiência, por outro lado, contudo, assinalam-se aspectos em que ainda estamos atrasados e em dívida com a sociedade.

Diante das metas traçadas no PDI e explanadas neste trabalho, no ano de 2014 a Coordenações de Políticas de Diversidade e Inclusão - CPDI desenvolveu suas atividades de forma a propiciar orientação, acompanhamento e supervisão aos campi 
conforme cronograma estabelecido no Planejamento das ações anual, visando atender as metas definidas. As ações executadas pela CPDI foram:

- Orientação, acompanhamento e supervisão dos coordenadores dos NAPNEs, através de visitas pedagógicas e realização de quatro encontros anuais para planejamento e ajuste de funcionamento deste núcleo;

- Orientação, acompanhamento e supervisão dos Tradutores Intérpretes de Língua Brasileira de Sinais/Língua Portuguesa - TILS, através de visitas pedagógicas e realização de dois encontros anuais para planejamento e ajuste planejamento de trabalho (projetos de pesquisa, extensão e acompanhamento dos surdos);

- Criação com a Pró-Reitoria de Extenão - PROEX, de vagas em edital para todos os campi de cursos de extensão em Libras, com o objetivo de atender a comunidade externa e interna, no que diz respeito à capacitação, uso e difusão da Língua Brasileira de Sinais;

- Criação do Núcleo de Pesquisa em Inclusão e Diversidade: do social ao pedagógico - NID, que nasce com o objetivo geral de alavancar as pesquisas, principalmente no estado do Mato Grosso, direcionadas à inclusão e diversidade, contribuindo para que todos possam ter uma participação plena na vida acadêmica e em sociedade.

- Participação no $3^{\circ}$ WORK IF - Workshop de Ensino, Pesquisa e Extensão do IFMT com divulgação dos trabalhos de pesquisa realizados pelo NID através de palestras, comunicação oral, apresentação de banner e mesas de discussões;

- Participação nas discussões realizadas no I Encontro Estadual de Professores da Educação Básica do IFMT, tendo como público professores, gestores e alunos deste nível de escolaridade;

- Participação em eventos nacionais voltados para a inclusão, como o I Congresso nacional de inclusão na Educação Superior, promovido pelo Ministério da Educação em Natal/RN;

- Atendimento pedagógico especializado aos professores, equipe gestora e multiprofissional e corpo discente dos campi, no intuito de esclarecer situações específicas voltadas para inclusão e diversidade, e capacitar continuamente para melhor atendimento das pessoas com necessidades específicas;

- Discussões em comissões específicas na busca de instituir a política de acessibilidade e apoio às pessoas com deficiência no IFMT; 
- Fiscalização e incentivo à adequação dos prédios já existentes e em construção do IFMT, promovendo a acessibilidade física por meio da remoção de barreiras arquitetônicas;

- Fomento o desenvolvimento de políticas, projetos e ações afirmativas em respeito às diversidades (sexual, de gênero, étnico-racial, religiosa, socioeconômica, etc.) e na busca da inclusão social e da igualdade;

- Discussões e estudos sobre meios de promover o desenvolvimento de recursos didáticos e pedagógicos voltados à inclusão e diversidade no âmbito do IFMT;

- Apoio nas avaliações dos Projetos Pedagógicos de curso quanto à adequação dos mesmos, para a promoção da inclusão e valorização da diversidade;

- Incentivo à contratação por meio de concurso de novos servidores capacitados para a área, bem como o reconhecimento daqueles que já atuam, entre outros.

Dentro das mais variadas linhas de trabalho voltadas para o atendimento dos estudantes com deficiência (cego, surdo, baixa visão, surdocego, cadeirante, deficiente intelectual, etc.) e com necessidades específicas (indígenas, mulheres em situação de vulnerabilidade e outros, idosos, etc.) e, para que este atendimento seja efetivado com qualidade, é importante primeiramente e constantemente realizarmos a sensibilização dos âmbitos onde estamos inseridos, e dessa forma buscamos, em tempos oportunos realizar sensibilização com os dirigentes máximos gerais (reitores, pró-reitores, chefes de departamento), seguindo para as gestões locais nos campi (Diretores Gerais, Chefes de Departamento de Ensino e Coordenadores de cursos), bem como os professores e técnicos (servidores em geral) e os estudantes.

É imprescindível também conhecer as peculiaridades culturais e identitárias de cada limitação, bem como apreciar os temas transversais que envolvam os questões "inclusão" e "direitos humanos", buscando delinear os caminhos institucionais para o cumprimento da legislação vigente no Brasil, dessa forma, seguindo os princípios expostos no Plano Nacional de Educação em Direitos Humanos (PNEDH, 2006) e no Estatuto da Pessoa com Deficiência (BRASIL, 2015).

Dessa forma, realizamos o levantamento das ações já existentes através do contato com os Coordenadores dos Núcleos de Atendimento às Pessoas com Necessidades Específicas - NAPNE nos campi, no intuito de conhecermos a atuação deste instituto na sociedade na promoção de inclusão à diversidade, ou seja, o 
atendimento aos direitos humanos, já que essa investigação que envolve o campo das ciências humanas e sociais.

Diante das atividades já realizadas, em andamento e as planejadas para curto, médio e longo prazo, podemos perceber uma importância maior a ser dada pela instituição às ações de inclusão e diversidade, e um interesse maior em atender a todos com igualdade, respeitando as diferenças.

Desde a fundação da CPDI, as discussões têm se ampliando sobre inclusão e diversidade, e um exemplo claro que constata essa realidade é encontrarmos no PDI 2014/2018 todo um capítulo, intitulado "Políticas e metas em direitos humanos", dedicado às discussões e metas a serem alcançadas neste âmbito durante os quatro anos vindouros, situação não encontrada no PDI anterior (2009/2014).

A Coordenação de Políticas de Diversidade e Inclusão deste Instituto Federal de Educação, Ciência e Tecnologia de Mato Grosso - IFMT, funcionando já há aproximadamente três anos, tem observado e se esforçado para dar atenção necessária às necessidades de todos aqueles que adentram ao âmbito do IFMT, buscando atendê-los com igualdade e adequadamente às suas limitações e precisões, através dos NAPNEs nos campi.

Dentro do trabalho já realizado e dada a abrangência do tópico, percebemos a necessidade de ampliarmos nossas pesquisas documentais no que diz respeito à análise aprofundada dos últimos dois PDIs do IFMT, pesquisar as legislações existentes sobre a diversidade, a começar das leis internacionais que envolvem inclusão, até as nacionais que focam no tratamento igualitário.

A nossa pesquisa foi realizada de modo simplificado para mostrar que o IFMT tem mostrado interesse em atender a legislação vigente no país, tendo assim, nosso estudo, uma abordagem qualitativa, uma vez que não exige preocupações numéricas, mas, busca compreender fenômenos procedentes de determinados grupos sócias de qualquer natureza (GERHARDT; SILVEIRA, 2009, p. 31).

O primeiro passo da pesquisa se realizou ao nos debruçarmos em algumas legislações existentes que tratam da diversidade e inclusão das pessoas com deficiência e com necessidades específicas na sociedade, mais especificamente no âmbito desta instituição educacional, e os aspectos educacionais referentes a essa comunidade, caracterizamos como pesquisa documental, que segundo Fonseca (2002, p. 32): 
A pesquisa documental recorre a fontes mais diversificadas e dispersas, sem tratamento analítico, tais como: tabelas estatísticas, jornais, revistas, relatórios, documentos oficiais, cartas, filmes, fotografias, pinturas, tapeçarias, relatórios de empresas, vídeos de programas de televisão, etc.

A análise dos dados considera três eixos temáticos: Legislação vigente no campo dos direitos humanos e inclusão, ações já realizadas neste campo no IFMT e por fim, avaliação conceitual do cumprimento dos parâmetros legais.

\section{Notas Conclusivas}

O levantamento de ações e a reflexão levada a cabo no presente trabalho revelam a crescente atenção dada ao cumprimento dos direitos humanos no Instituto Federal de Educação, Ciência e Tecnologia de Mato Grosso - IFMT, mas revela, igualmente, que ainda existe uma longa caminhada a ser trilhada num foco igualitário.

Neste sentido, o IFMT deverá buscar esse resultado através da sensibilização e da valorização do sujeito em todos os âmbitos desta Instituição educacional, sempre baseados na legislação que ampare esta visão de mundo, incluindo em seus currículos e planos de cursos temas como valores éticos, história dos direitos humanos, pluralidade étnico-racial, política, cidadania, democracia, respeito à diversidade, diálogos interétnicos e interreligiosos, mecanismos de proteção dos direitos humanos e outros (PNEDH, 2009).

O olhar diferenciado da sociedade sobre o ser gera afastamento ou aproximação sob este mesmo olhar, limitando a forma de convívio destes sujeitos com os outros não iguais a ele e nessa perspectiva surge o Plano Nacional de Educação em Direitos Humanos, que veio reforçar as garantias legais para toda população brasileira igualitariamente, principalmente no que diz respeito à saúde, educação e cidadania, e nessa população estão citadas pela Lei suprema as PcDs, a Constituição Federal de 1988, à época chamadas ainda de "Portadores de Deficiência", até as legislações mais recentes.

Dessa forma, as políticas de educação e Direitos Humanos tratam de valores, relações e práticas sociais e institucionais, numa perspectiva que não dissocie conhecimento, atitude, sentimento e prática, pautando-se em fundamentos que tenham 
uma concepção ética e crítica da educação, no que se refere à pedagogia participativa e dialógica.

O trabalho agora iniciado tem um caráter exploratório, e precisa ser aprofundado para obtermos dados mais precisos e mais amplos que nos ajudem e adesenvolver a cultura institucional e avançar no atendimento adequado e igualitário a qualquer ser humano, promovendo assim o cumprimento legal e o princípio de equidade entre cidadãos.

\section{REFERÊNCIAS}

BRASIL. Comitê Nacional de Educação em Direitos Humanos. Plano Nacional de Educação em Direitos Humanos - PNDH. MEC/MJ, UNESCO, 2006.

BRASIL. Constituição da República Federativa do Brasil de 1988. São Paulo, Saraiva, 2004.

BRASIL. Lei No 9.394, de 20 de dezembro de 1996. Estabelece as diretrizes e bases da educação nacional. MEC/SEC, Brasília,1996.

BRASIL. Lei $\mathbf{N}^{\mathbf{0}}$ 11.892, de 29 de dezembro de 2008. Institui a Rede Federal de Educação Profissional, Científica e Tecnológica, cria os Institutos Federais de Educação, Ciência e Tecnologia, e dá outras providências. MEC/ SEESP, Brasília, 2008.

BRASIL. Lei $\mathbf{N}^{\mathbf{0}}$ 13.146, de 6 de julho de 2015. Institui a Lei Brasileira de Inclusão da Pessoa com Deficiência (Estatuto da Pessoa com Deficiência). MEC/ SEC, Brasília, 2008. Diário Oficial da União República Federativa do Brasil, Brasília, DF, 07 jul. 2015. Disponível em: <http://www.planalto.gov.br/ccivil_03/_Ato2015-2018/2015/ Lei/L13146.htm>. Acesso em: 20 jul. 2016.

BRASIL. Programa Nacional de Direitos Humanos (PNDH). Brasília: SEDH/PR, 2009.

BRASIL. Política Nacional de Educação Especial. Brasília: MEC/SEESP, 1994.

FONSECA, J. J. S. Metodologia da pesquisa científica. Fortaleza: UEC, 2002.

GERHARDT, T. E. SILVEIRA, D. T. (org.) Métodos de pesquisa. Coordenado pela Universidade Aberta do Brasil - UAB/UFRGS e pelo Curso de Graduação Tecnológica - Planejamento e Gestão para o Desenvolvimento Rural da SEAD/UFRGS. - Porto Alegre: Editora da UFRGS, 2009.

IFMT. Instituto Federal de Educação, Ciências e Tecnologia do Mato Grosso. Normativa NAPNE. Resolução n⿳0 043, de 17 de setembro de 2013. 
IFMT. Plano de Desenvolvimento Institucional (PDI) 2009/2014. Cuiabá/MT, 2009. Disponível em: <http://pdi.ifmt.edu.br/wp-content/ uploads/2014/02/PDI-20092014.pdf >.Acesso em: 18 mar. 2015.

IFMT. Plano de Desenvolvimento Institucional (PDI) 2014/2018. Cuiabá/MT, 2014. Disponível em: <www.ifmt.edu.br/get_file/2000012/ 1001441/0/> - Acesso em: 18 mar. 2015.

\section{Como referenciar este artigo}

CORDEIRO, Suammy Priscila Rodrigues Leite. Agir a favor da inclusão: IFMT em ação. Revista Ibero-Americana de Estudos em Educação, Araraquara/SP, v. 11, n. esp. 3, p.1661-1673, 2016. Disponível em: <http://dx.doi.org/10.21723/riaee.v11.n.esp3.9066>. E-ISSN: 1982-5587.

Submetido em: agosto/2016

Aprovado em: novembro/2016 